\title{
The Study on the Design of Taoist Cultural \& Creative Products Based on Wuhan Intangible Cultural Heritage Resources
}

\author{
Zhiqiang Liu ${ }^{1}$ \\ Art and Design College \\ Wuhan University of Science and Technology \\ Wuhan, Hubei \\ 418913095@qq.com
}

\author{
Zhengyang $\mathrm{Li}^{2 *}$ \\ Art and Design College \\ Wuhan University of Science and Technology \\ Wuhan, Hubei \\ 532499906@qq.com
}

\begin{abstract}
The article analyzed Taoist culture in religious culture, Wuhan intangible cultural heritage resources and its significance in modern design and practice, which promotes the diversity of fixed "Wuhan image". "Its beneficial cultural elements" has been continuously developed in modern society for accepting, melting, reconstructing Changchun traditional culture. The research takes the case as mainline to express author's idea, indicate subject's generalizability by specific cultural and creative products design as well as propose improvement suggestions.
\end{abstract}

Keywords-Wuhan; City image; Taoist; Changchun temple; Cultural and creative products

\section{INTRODUCTION}

Wuhan is located in the center of the nine provinces thoroughfares, where has rich Taoist culture and intangible cultural heritage; As an indigenous religion, Taoism has a long history and deepest contact with the nation, with extensive cultural influence, Changchun Taoist templeis located in Wuhan and has a long history and can be a representative among them and deposited many diggable cultural elements, However, there are not many cultural and creative products of this kind, and the propaganda is insufficient. Taking the design of Changchun Guan Taoism element cultural and creative products as an example, this article integrates the Taoist elements of Changchun concept with the non-heritage skills of Wuhan and surrounding areas through borrowing and metaphor and studies the connect ability between the intangible and Taoist cultures in Wuhan. To help diversify Wuhan's urban image.

\section{Generalization OF WuHAN INTANGIBLE HeRITAGE AND TAOIST CULTURE}

\section{A. Wuhan intangible heritage}

\section{1) Han embroidery}

Wuhan and its neighboring existed diverse intangible cultural heritages which plays a positive role of shaping Wuhan image. The arts and crafts represented by Han embroidery have extensive connections with people's lives and religious beliefs. Han embroidery based on Chu embroidery melted merits of northern and southern embroidery skills and kneaded out new embroidery method with vivid local characteristics. With inheritance and development of history, Han embroidery became one of representatives of Chu and Han cultures [1]. Undoubtedly, its cultural inside information is soul of the city if economic development regarded as urban heart. Dense color and bold collision collocation of Han embroidery is cultural basis and urban soul of WuHan, a furnace city. As typical representative of Jingchu folk culture, we believe that the cultural connotation of Han embroidery has not been fully developed and applied in modern times, its subject matter and form is deviated from era development.

\section{2) Wuhan intangible heritage of $8+1$ urban circle}

Wuhan urban circle means the city circle centers on Wuhan, the largest city in middle area and covers eight large-middle cities Huangshi, E'zhou, Huanggang, Xiaogan, Xianning, Xiantao, Tianmen and Qianjiang. The intangible culture heritages included in the range has significant effect to shape Wuhan modern image. Yangxin cloth paste and Huangmei flowers picking are intangible culture heritages in Wuhan neighboring areas. Yangxin cloth paste means pasting various patterns on cloth in deep color. But Huangmei flowers picking is based on the cloth in deep black and use five-color silk thread thread in crossed gird of longitude and latitude of bottom cloth, then bright and cubic pattern is formulated.

\section{B. Taoist culture as representative of Changchun temple}

In the letter To Xu Shouchang by Lu Xun, there were sayings that "the root of Chinese culture is in Taoism". Which explained Taoist culture is important in traditional Chinese culture......some influence cannot be ignored in nowadays. [2]Among the many Taoist Wuhan branch of them, through historical development and baptism, Changchun Taoist sects as the representative of the genre best preserved, its color, utensil, language and words have representative meaning in expressing Taoist spiritual connotation as well as the reason of regarding the Changchun Taoist culture as example. Taoist culture includes following aspects: Taoist theology is combined by Taoist immortal belief which has independent theory since ancient times and absorbed foreign gods with change of the times. And improved and giant Taoist theology system was

2017 National Social Science Fund of China of Art Project.NO.160.Research and Development of Cultural and Creative Products Based on Museums-Level Assessment Criteria. Phased Research Results.

Pong Heng. Wuhan University of Science and Technology. 
created through series cultural activities. In philosophy, Cosmology and epistemology are ornaments and argumentation tool of its life theory, but the core of life theory is study of immortality which aims at solving live problems. [3]With improving of immortal theory system, Taoist medical science is regarded as channel and knowledge of long-life for believer. There formulated many health maintenance method through endless practice and deposition. But Taoist culture and arts promote doctrine by reflecting artistic works subject to Taoist life. The immortal patterns, musics, buildings in Taoism have a high artistic value. The artistic works takes Taoism immortals as elements is numerous, the firm connection between Taoism and art can be seen from here [4].

Above all, Wuhan and its neighboring areas reserved rich historic cultural heritages bring rich urban culture and connotation storage to Wuhan. These excellent cultural heritage have become the representative of Wuhan image through inheritance and accumulation, it not only existed in museums and documents but should return to life selectively without apply mechanically and interpret out of context but have symbolism, artistry and practicality.

\section{AnAlysis of CURRENT CUltural AND CREATIVE PRODUCTS OF CHANGCHUN TEMPLE}

Through interviewing, investigating and viewing documents, author found there is no paper or research about Changchun culture and creation, However, the research on Taoist cultural \& creative products is mainly based on Wudang Mountain through CNKI, Wanfangdata.currently, the cultural and creative products sold in Changchun temple is goods of Taoist artifacts-based ornaments, as picture 1, the goods in there is same with other Taoist temples or markets as well as no features although there appeared some tentative designs about modernized ancient elements. The cultural and creative products is carrier of culture, it affected and restricted by specific culture but most of combination is too stiff, [5] most of them are made simply by copying Taoist patterns or traditional Taoist appliances sold directly.

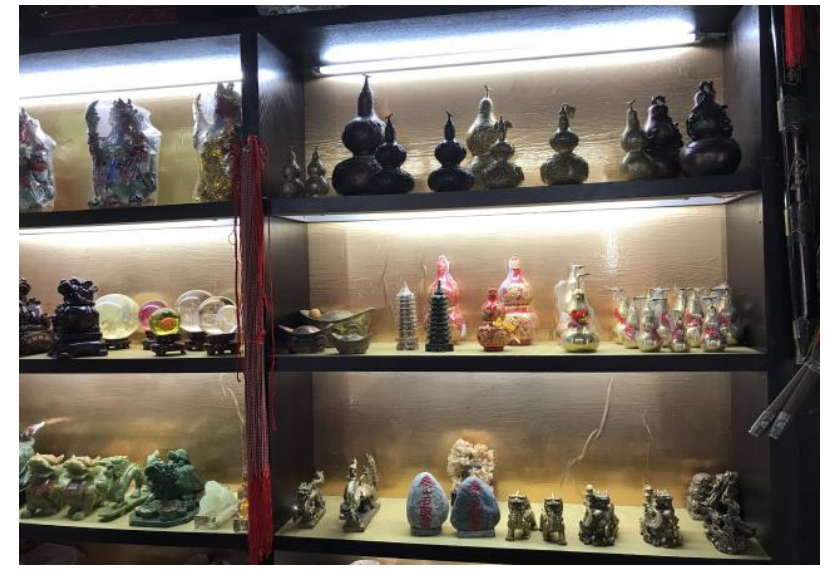

Fig. 1. THE souvenir STORE OF WUHAN CHANGCHUN TEMPLE
In terms of cultural and creative products, the British Empire Museum has many ideas for us to learn from, products design is a material culture and creation, any product has its corresponding cultural value [6] and their cultural and creative products combined different cultures or made deep evacuation to single culture, for instance, Take the Rosetta stone tablet as an example, there are hundreds of cultural \& creative products.

We can see from analyzing current cultural and creative products of Changchun temple that though Taoism culture in Changchun temple is utilized in a degree, Its personality in the Wuhan area is still not obvious. At the same time, Wuhan and its surrounding intangible cultural heritages craftsmanship are also in urgent need of development and innovation. Cultural and creative products should contains form and spirit, with an all-round cubic exhibition as urban appearance, which is not only the simple copy of plane image of elements but more cubic performance, so that the expressible culture will be more vivid.

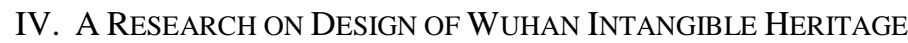 RESOURCES, TAOIST CUlTuRAL AND CREATIVE PRODUCTS}

Qing Xitai thinks Taoism is production of Chinese social historic development and evolution of Taoism itself, which is a giant and complex though system led by "Taoism". [7]There appeared rich and elegant patterns while Han embroidery and other folk arts supply massive goods to senior society and religious etiquette, which can be the national culture and embody it in cultural and creative design. Intangible cultural heritages and cultural and creative design is mutually connected, excellent cultural and creative design can utilize cultural connotation of intangible cultural heritages rationally [8]. Traditional culture has new vitality and direction as combing embroidery skills and Taoist cultural and creative products, it can be full of artistic quality while has practicability, spread Taoist theoretical culture by metaphor and other methods and give emotional hope to people's life in metropolis where have modern quick tempo and quickly developed hi-tech. Many Intangible cultural heritages with mutual connection can melt and develop with cultural resources mutually, which has full publicity space of development for Wuhan image. We made available case as table I according to specific performance feature of Taoist culture and features of Wuhan neighboring intangible handicraft arts. 
TABLE I

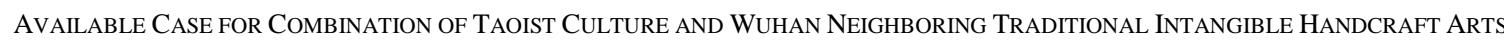

\begin{tabular}{|c|c|c|c|}
\hline Taoistic Cultural Type & Specialty of Changchun temple & Philosophy thoughts & Representative colors \\
\hline Han embroidery & Pattern reduction & Connotation depiction & Combination \\
\hline Cloth paste & Exhibition of cubic effect & Concretize spirit & Bulk application \\
\hline Flowers picking & Expression of geometric form & Spirit brief materialization & Blend in background color \\
\hline $\begin{array}{c}\text { Type of cultural and } \\
\text { creative product }\end{array}$ & $\begin{array}{c}\text { Paperweight, censer, book-end, miniature } \\
\text { landscape and so forth }\end{array}$ & $\begin{array}{c}\text { Incense utensils, writing brush, } \\
\text { inkstone, paperweight and so forth }\end{array}$ & $\begin{array}{c}\text { Book, greeting card, postcard, label } \\
\text { and so forth }\end{array}$ \\
\hline $\begin{array}{c}\text { Taoistic Cultural Type } \\
\text { Han embroidery }\end{array}$ & Special patterns & Representative implements & Representative animals \\
\hline Cloth paste & Pattern reduction & Cubic pattern & Concretize pattern \\
\hline Flowers picking & Changeable pattern & Simple pattern & Modernized image \\
\hline $\begin{array}{c}\text { Type of cultural and } \\
\text { creative product }\end{array}$ & Seat, table, tea table and so forth & Tableware, tea set, air cleaner and so \\
forth & $\begin{array}{c}\text { animation role, game character and } \\
\text { so forth }\end{array}$ \\
\hline
\end{tabular}

\section{A. Cultural and creative design combing symbolic amulet} and intangible heritage

Culture is exteriorization and objectification of human being; it is realization and concrete of symbol activity-Cassill [9].Amulet is to transmitting information as the representative of symbol, at the same time, everything in the cosmos is in the same sense as the human heart, and it has human spirituality, which conducted an vital conception----ghost concept, ghost has ability of controlling world and human beings, as well as five-thunder token and emperor bell. Meanwhile, Taoism image needs deep modern interpretation and have become language and visual treasures in our modern artistic creation [10].Therefore, it can be applied in design of Taoist cultural and creative products by this relation and it will play a more unique visual effect through combining with Han embroidery skills.

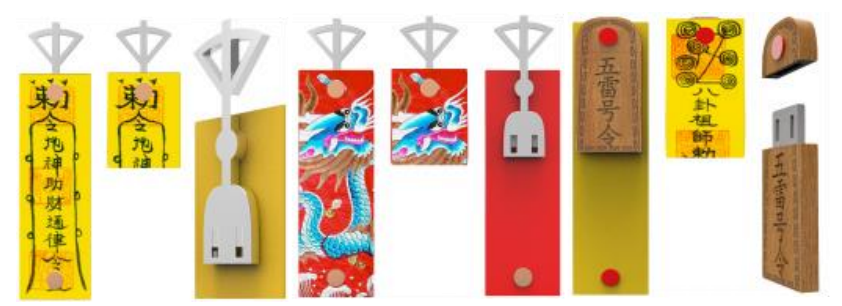

Fig. 2. Series of amulet U-disc

As picture 3, the U-disc series design of combining two great elements of emperor bell and five-thunder token and traditional Han embroidery works with Taoism amulet, as picture 3, amulet elements as major background allocated with different colors and U-disc parts with different modelling, emperor bell or token modelling are entity of U-disc, lower part of emperor bell is U-disc, token is open-covered U-disc, package part is similar to amulet, extracting major color and image of two cultures for suiting modern design aesthetics, which not only can protect U-disc but can increase beauty. And it reached target of combining artistic quality and practicability while expressing metaphor of anti-poisonous U-disc.

Applying the part from Taoism amulet which is correspondent with modern life and combine the goods in modern life, with assistance of intangible cultural heritage handicraft arts to bring some traditional cultural elements to digital products which not only can enrich people's visual feeling but can play the role of promoting "beneficial culture".

\section{B. Research on the design of Taoist classical appliance and modern cultural and creative products}

There are many touchable Taoist appliance in daily life except Taoist amulets. These Taoist appliances has been witnessed and experienced long course of development traditional Chinese artifacts culture [11]. The classic artifacts in these Taoism are also integrated into the design of modern cultural and creative products through symbolic and simplified forms, which not only can enrich classification of Taoist cultural and creative products in Changchun temple and improve its contained cultural connotation, but can expand influence of Taoist culture in Changchun temple to people.

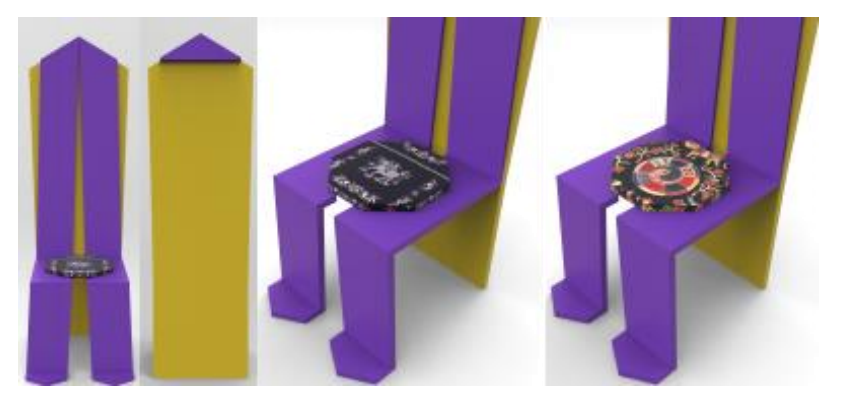

Fig. 3. design of Huijian seat

As picture 4, design of abstract Huijian seat. Huijian is a kind of ornamentation of priest frock. That is made by two long band and sewn in button of priest frock. The so-called "jump out of bitter environment by powerful wisdom sword", that's the meaning of wisdom sword. Taking the abstract Huijian as the main element, it is designed as a high straight seat. The whole blue part is cubic buckling like Huijian, the back of a chair is simplified token pattern, chair cushion is soft and simplified eight diagrams cushion, the surface pattern of cushion adopted Huangmei flowers picking and Yangxin cloth paste crafts, all of patterns are relate to Taoist culture. Through simplify the design of Taoist elements to exhibit Huijian the 
plane Taoist element and assisted with traditional handcraft arts, in order to both close to modern aesthetics by high-straight type and make people have full associate space by abstract design.

Through extracting elements and marks of Taoist garments and objects, which can embody its cultural connotation mostly, combines with modern life goods or life scens to bring some different cultural and creative products by simplified abstract method to people, enrich people live and improve spreading of traditional culture.

\section{Research on the design of Taoist language words and modern cultural and creative products}

"To say other things before saying what is the theme; to compare the theme to other things; to say other things first to lead to the theme." These are the words by Zhu Xi of Song Dynasty [12]. To express the abstract Taoistic culture through concrete object, especially the rich cultural significance in Taoism world and its symbol, the way can inspire our cultural and creative product design.

Taoist world view thinks that the world is in constant movement and change and it can be transformed mutually, there are some Chinese words originated from these Taoist thoughts and Taoist classics. As the great ultimate, theory that man is an integral part of nature, mystery of mysteries as picture 5 (from Huaban), the great bookshelf is designed from the "Tai Chi", "Tai Chi" bookshelf means Taoist inclusiveness and its books means endless knowledge is hidden in oceanic Taoism. The use of these set phrases enriched expression effect of language. Some Taoist classics have massive set phrases, most of them are from Laozi like "a great man becomes famous late in life" which is from Laozi• Morality Scriptures: "generous without a corner, a great man becomes famous late in life, great sound is hard to hear, great form is beyond shape." "enduring as the universe" is from Laozi•Taoism Scriptures: "the reason of why heaven and earth can live long is for not living on its own." Others like have a mind as open as a valley, Taoism nature, great success is lacking, great art conceals itself, retire after winning merit. It can bring deeper spiritual feeling to people by these thoughts and cultures, as well as including rich cultural connotation to cultural and creative products while making Taoist culture known by public greatly.

Subject group designed an incense with meaning of "mystery of mysteries", as picture 6, it is simple at first glance, the top stage can be revolved, while a profound theory contained inside, incense, ash collection box are included in it, which means Taoist rich connotation and mysteries. The stage is connected with inner ash collection box and the ash can be swept into it, so the whole dump is omitted.

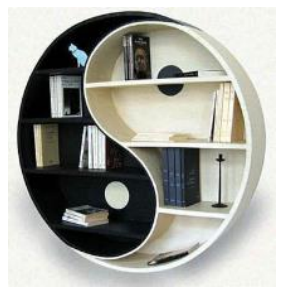

Fig. 4. The great diagrams

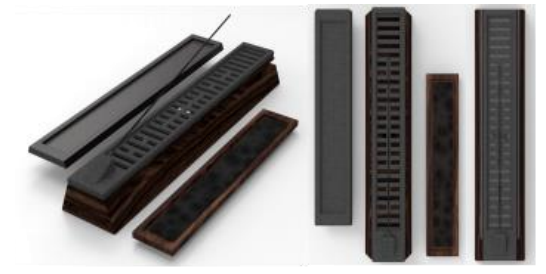

Fig. 5. Incense of "mysteries"

\section{CONCLUSION}

Taoist temple not only has nature of collection and exhibition as a temple connecting tradition and modern, but has mission of developing and expanding traditional culture as well as a best place of spiritual sustenance, the research melted Wuhan and its neighboring intangible culture heritage handicraft arts by referring products design methods, rediscovering and reused Taoism elements of Changchun temple and Wuhan traditional culture, through the screening of traditional cultural elements, we have found a beneficial culture that is in line with the times and has positive significance. We hope the research can re-consolidate cultural deposit of Wuhan and it plays a favorable role in diversifying Wuhan image and improving its cultural soft power. Meanwhile, there are many places in Taoist series cultural and creative products can be developed, we look forward scholars to improve and enrich our cultural and creative products in order to improve our national image with diverse cultures.

\section{REFERENCES}

[1] Liang Huiyin: Research on the Value of Jingchu Artistic Han Embroidery [J], Science and Education Literature (last monthly ten-day edition), Aug 30, 2008. (In Chinese)

[2] Qing Xitai: Location and Modern Value of Taoist Culture in Chinese Traditional Culture $[\mathrm{J}]$, Journal of Hunan University (social science edition), volume 20th, term IV, July 2006. (In Chinese)

[3] Li Gang: Feature of Taoist Living Philosophy [J], Jiangxi Social Science, Sept 2004, 52-60. (In Chinese)

[4] Baidu Wikipedia, Taoism Cultures[OL], http://baike.baidu.com/link?url=6MOXA68kieeipZBzGQrbjVY6flyyIK G9BgCed9ym0Sv_qpP4Fp9b2Sf8cySKimGXdtVvG_KIfaSWvy5taWdt mJ8a60VHME7x6A1tF3ERERqoq8di_T7oRbG2_NKRB6cE.(In Chinese)

[5] Sun Shuying: Experience Innovative Design of Tourism Products [J], China's Market, June 2011, 102-103. (In Chinese)

[6] Qing Xitai: Chinese Taoist History (volume 1) [M], Sichuan People's Publishing House, 1992, page 146. (In Chinese)

[7] Li Fuxing, Dong Jixian: Interpretation to Traditional Cultural Mark in Products Design [J], Packaging Engineering, 2009, 132-136. (In Chinese)

[8] Wang Yimin, Liu Yuanyin: the Effect of Form and Meaning of Intangible Heritage Culture to Products Design [J], Packaging Engineering, May 2005. (In Chinese)

[9] [German]Cassill: Theory of Man [M], Shanghai Translation Publishing House, $1985: 33 ; 35 ; 8 ; 15 ; 2 ; 88 ; 87$.

[10] Li Juntao: Modern Interpretation and Visual Research Value of Taoist Art [J], Ornament, July 2012. (In Chinese)

[11] Cheng Qun: Observation to Religious Cultural Spirit of Taoist Appliances [J], Cultural Heritages, Jan 2014. (In Chinese)

[12] Song dynasty• Zhu Xi Anthology of Poems volume I. (In Chinese) 